\title{
Effect of Yoga on Physical and Mental Health of Climacteric Women in the Context National Fitness
}

\author{
Lingmin $\mathrm{He}^{1, *}$
}

${ }^{1}$ Sports Department of Xiamen University of Technology, Xiamen, Fujian 361024, China

*Corresponding author.

\begin{abstract}
Under the influence of nationwide physical fitness campaign, more climacteric women took part in various sports. But not all sports are suitable for climacteric women. Most studies show that yoga has a strong effect on improving the physical and mental health of climacteric women. Therefore, in this study, two groups of climacteric operation were used as comparative subjects, and different groups of yoga group and control group were set up, and different sports items and rehabilitation methods were provided respectively. The results show that the participation of menopausal women in yoga is beneficial to physical and mental health. Therefore, yoga can be used as an important item to promote the national fitness program and improve the condition of climacteric women.
\end{abstract}

\section{Keywords: national fitness, female climacteric, yoga exercise, physical and mental health, evaluation mode}

\section{INTRODUCTION}

Female climacteric is easy to produce MPS perimenopausal syndrome. It is a set of syndrome in a series of autonomic nervous system dysfunction, accompanied by neuropsychological symptoms, due to the fluctuation or reduction of sexual hormones in women's menopause [1]. At this time, the physical quality and psychological state of climacteric women are extremely unstable, which greatly interferes with their normal physiological activities [2]. Most studies have shown that yoga exercise can adjust the physical and mental health of women from both physical and psychological conditions. It is of great significance in the development of sports and physical fitness in the people of the People's Republic of China [3].

The development of sports for all is aimed at the cultivation of all social sports. The climacteric women can participate in sports less, any excessive sports will lead to menopausal women's physical fitness [4]. The yoga exercise takes women's physical quality as the precondition, which meets the sports needs of climacteric women. This is the basic condition for the participation of more climacteric women in the national fitness program [5]. Therefore, this paper compares the physical and mental health status of climacteric women after practicing yoga, so as to provide theoretical reference for related research.

\section{RESEARCH METHODS}

\section{A. Selection of research objects}

A total of 126 climacteric women were randomly divided into the yoga group and the control group, with 63 women in each group. The basic data of age, systolic blood pressure, diastolic blood pressure and body mass were similar between the two groups before receiving rehabilitation treatment [6]. The two groups of women were closer to the SDS self-rating depression scale of their mental state, and could be used as a comparative study to compare the health of the two groups of women in physical and mental quality, and it can help to further understand the positive effects of yoga for menopausal women.

\section{B. Research method design}

Women in the control group were given independent management at the experimental stage. The daily exercise dancing or walking is very good for menopausal women. But it is not necessary for climacteric women to complete the exercise and give some women poor mental health medication [7]. Yoga group in the fitness center organized climacteric women in the hospital to participate in yoga. They set up 3 yoga sessions daily, from the climacteric women to choose free classes, to maintain the minimum 12 sessions per week. The contents of the course include the teaching contents of yin yoga, ball yoga, flow yoga, hatha yoga, double yoga, group yoga, air yoga, and alange precision physiotherapy yoga [8]. According to the physical quality of menopause, flexibility, balance, and limb strength, the maximum strength of the climacteric 
women is the training target, and the support effect of yoga on the physical quality and mental state of the menopause women is summarized.

\section{Evaluation criterion}

On the one hand, the evaluation standard of physical quality is based on two groups of climacteric female body mass, diastolic pressure and systolic pressure, and the adjustment effect of physical quality in the 18 week training cycle is determined [9]. On the other hand, the evaluation index of mental status is based on the score of SDS self-rating scale. The higher the score is, the worse the mental state adjustment effect of climacteric women is. Less than 53 points means there is no depression, which is a positive manifestation for mental health. 53 62 points is considered as middle depression. 63 72 points has been moderately depressed, and more than 73 points belongs to deep depression.

\section{Operation model}

On the one hand, body health indicators consist of body mass $S_{i}$, diastolic blood pressure $U_{\tilde{j}}$ and systolic blood pressure $Z_{K}$. The function expression of the evaluation model of physical quality is

$$
\mathrm{D}_{(s, u, z)}=\frac{\sum D_{i j}\left(U_{j}-Z_{k}\right)_{i j}}{1-\left[\sqrt[\frac{1}{t}]{\left(S_{0}-S_{i}\right) / n}\right]}
$$

In this formula, $D_{i j}$ represents the change in physical health of climacteric women during the overall treatment cycle. When the three indexes of body mass,

$S_{i}$ diastolic pressure $U_{j}$, and systolic pressure $Z_{K}$ gradually tended to the health level, the representation of the female had improved the physical quality, which was the support of the yoga exercise for the menopause women's physical state [10].

On the other hand, the psychological evaluation model of menopause women, according to the psychological state characteristics of menopause women set related problems, to investigate the psychological reflection of the state of the surrounding things [11]. A total of 45 mining points were set up. Each mining point was divided into weights according to the importance, and finally the psychological characteristics were classified, and the characteristics of psychological state were summarized. The function expression of its psychological evaluation model is

$$
Y_{i j}=\sum_{i \in j}^{i^{-}} Q_{n} / 45 \times 100
$$

In this formula, $Q_{\mathrm{m}}$ represents the total score of climacteric women when they answer psychological problems. After the mental assessment standard of the total score in 45 problems is clear, it can be summed up by the self-evaluation of the climacteric women to make a relatively objective systematic evaluation of the psychological intervention effect produced by the yoga movement.

\section{E. Statistical method}

Below are two groups of climacteric women in the experimental stage of the relevant data into SPSS 19 statistical software according to mathematical analysis and statistics. Enumeration data are identified by (\%) percentage and tested [12]. The measurement data were identified by and test. The difference between was statistically significant.

\section{Statistical RESUlt}

\section{A. Effect of two groups of climacteric women's physical quality}

After 18 weeks of experiment, the physiological level of the menopause women in the yoga group is better than that of the control group. The systolic and diastolic pressure is close to the normal value, and the body quality tends to the normal physiological state obviously. While the physiological indexes of menopausal women in the control group tended to be stable, but it did not reach the intervention effect of yoga group [13]. There was a high difference in the results of multiple data and statistically significant. The effect of two groups of menopausal women on physical fitness is shown in "Table I".

The effect of two groups of menopausal women on physical fitness is shown in "Table I".

TABLE I. THE PHYSICAL QUALITY OF POSTMENOPAUSAL WOMEN IN BOTH GROUPS AFFECTED THE EFFECT

\begin{tabular}{|c|l|l|}
\hline Group & $\begin{array}{c}\text { The yoga group } \\
(\mathbf{n = 6 3})\end{array}$ & $\begin{array}{c}\text { The control group } \\
(\mathbf{n}=63)\end{array}$ \\
\hline $\begin{array}{c}\text { Systolic pressure } \\
\text { (mmHg) }\end{array}$ & $127.01 \pm 5.521$ & $131.62 \pm 3.796$ \\
\hline $\begin{array}{c}\text { Diastolic pressure } \\
\text { (mmHg) }\end{array}$ & $73.55 \pm 3.752$ & $77.36 \pm 1.750$ \\
\hline $\begin{array}{c}\text { The body of the } \\
\text { quality }\end{array}$ & $55.32 \pm 6.312$ & $68.79 \pm 8.936$ \\
\hline
\end{tabular}

\section{B. Effect of two groups of climacteric women's psychological state}

The two groups of climacteric women in the experimental stage had a gradual recovery trend of depression. But the yoga group climacteric women after getting active exercise mode, its improvement effect is more obvious, better than the control group, the 
difference between the two groups is significant [14]. A has statistical significance. The psychological effects of two groups of menopausal women were shown in "Table II".

TABLE II. EFFECTS OF MENTAL STATES OF MENOPAUSAL WOMEN IN TWO GROUPS [N (\%)]

\begin{tabular}{|c|l|l|l|l|}
\hline Group & $\begin{array}{c}\text { There is no } \\
\text { depression }\end{array}$ & $\begin{array}{c}\text { Mild } \\
\text { depression }\end{array}$ & $\begin{array}{c}\text { Moderate } \\
\text { depression }\end{array}$ & Major depression \\
\hline The yoga group $(\boldsymbol{n}=\mathbf{6 3})$ & $59(93.65)$ & $3(4.76)$ & $1(1.58)$ & $0(0.00)$ \\
\hline $\begin{array}{c}\text { The control group } \\
(\mathbf{n = 6 3})\end{array}$ & $33(52.38)$ & $15(23.81)$ & $10(15.87)$ & $5(7.93)$ \\
\hline
\end{tabular}

\section{YOGA'S PSYCHOLOGICAL AND PHYSICAL ADJUSTMENT SUPPORT FOR CLIMACTERIC WOMEN}

\section{A. Regulation of the nervous system and the endocrine system}

On the one hand, yoga is a quiet exercise in a quiet environment in which the body can be adjusted to the best state of relaxation. The nervous system in control of the brain's central nervous system will also be relaxed, and then it effectively alleviates the subjective pressure caused by menopause. Practicing yoga for a long time can effectively regulate the nervous system and restore normal condition. On the other hand, because of the gradual decline of the ovarian function, the secretion of estrogen will also decrease. And yoga exercises can be practiced through various posture methods to stretch the limbs, and then enhance the physique of the menopause women. In the process of regulating the endocrine system, it also postpones the aging of women to a large extent, helps the women to restore the endocrine autonomic function, and reduces the symptoms of the menopause, such as hot flashes, sweating, insomnia and other psychological conditions.

\section{B. Strengthening the function of the body and improving the mental state}

On the one hand, the pursuit of harmony between man and nature in yoga is the perfect combination of breathing and action. As each movement proceeds, the gas in the body of climacteric females will also continuously release new particles, thereby enhancing lung capacity and respiratory function. At the same time, yoga exercise can also promote the blood circulation of the body and the gastrointestinal peristalsis to the maximum, and further improve the digestive function of the climacteric women's intestines and stomach, and have a certain support for the prevention and cure of the symptoms of menopause constipation. Therefore, it can be confirmed that yoga exercise has an effect on the physical function of climacteric women. On the other hand, during the yoga practice, the menopause women are in a relaxed state of mind for a long time, and the normal and relaxed yoga can relax the tense muscles to enhance the female body's endurance and flexibility. And this level of bodily regulation has indirectly played a role in beautifying the body lines and played a key role in the control of body fat. Therefore, after the improvement of the physical condition of the climacteric women, it will directly affect the adjustment of the psychological state. It can be concluded that yoga is carried out in an elegant environment, while relieving movement and external environment at the same time play a role in improving mentality. Menopause women will be in a highly relaxed state of mind and body, so it will reduce the phenomenon that the menopause women tend to be upset and so on. Even before the symptoms of insomnia, dreamy or depression and anxiety, they can be effectively adjusted by practicing yoga to restore their physical and mental health.

\section{CONCLUSION}

In a word, the yoga training for female climacteric is aimed at cultivating climacteric women to form good habits through breathing exercises, resting positions, stretching exercises and the adjustment of the diet scheme to solve many physical and mental health problems which are easily produced in the menopause. In this study, it was found that although the women of the control group were also involved in some sports, the effect of the exercise was obviously not an important role in improving the physical and mental health of the menopause women. And it is important yoga can improve menopausal women's physical and mental health after the long term training. The period of selfrecovery of the physical quality produces a selfregulated psychological state. Therefore, the yoga exercise can be used as an important sports resource to promote the physical fitness of the whole people, so that more menopause women can participate in it. It does improve their physical and mental health and is beneficial to the development of the whole people's physical and mental health. 


\section{References}

[1] Cao. X. H., Bai, Z. G., Gao, C. Y., Wu, H. Y., Wang, L. J., Xu, J., Ding, G. W. (2018): "Meta-analysis on the effectiveness of yoga in alleviating insomnia in perimenopausal period," Chinese Journal of Family Planning, VoL.26, No.02, pp.86-90.

[2] Li, Y. F. (2018): "Effects of yoga exercise on depression in menopausal women," Journal of Shaoguan University, VoL.38, No.09, pp.94-98.

[3] Xiao, W., Zhou, J., Zhang, W. C. (2016): "Research overview of exercise therapy for female menopause syndrome," Journal of Liaoning University of Traditional Chinese Medicine, VoL.18, No.12, pp.75-77.

[4] Pan, Y., Li, Z. X. (2018): "Experimental study on the effect of yoga exercise on the fitness of occupational women's health," Journal of Hubei Normal University (Nature Science Edition), VoL.36, No.01, pp.41-44+63.

[5] Zhang, R. Y. (2016): "Study on the changes of surface electromyogram signal in elderly women with chronic low back pain," Liaoning Sports Technology, VoL.38, No.01, pp.48-52.

[6] Chen, R. Q., Zheng, D. (2016): "Comparative study on the effects of yoga and mass calisthenics on balance ability of young women," Sports Research and Education, VoL.31, No.01, pp.102-105.

[7] Feng, W., Qiu, L. W., Bao, W. L., Li, C. X. (2015): "Treatment of chronic fatigue syndrome in professional women by yoga," Journal of Kunming Medical University, VoL.36, No.11, pp.158-161.

[8] Wang, C. H., Hu, H. Q., Feng, G. H., Zhang, X. W. (2018): "Effects of yoga on cardiac plant nervous dysfunction during menopause," Chinese Journal of Sports Medicine, VoL.33, No.10, pp.1019-1021.

[9] Qiu, P. (2014): "Study on the effect of yoga practice on relieving menopausal symptoms of menopausal women," Chinese Maternal and Child Health, VoL.29, No.22, pp.35803583.

[10] Zhao, A. E., Liu, H. Y. (2011): "Research on the improvement of mental and physical status of menopausal women by yoga exercise," Chinese Journal of Health Psychology, VoL.19, No.10, pp.1274-1276.

[11] Zhang, R. (2018): "Research on the influence of yoga on sleep quality of menopausal women," Value Engineering, VoL.30, No.25, pp.300-301.

[12] Yin, Y. J., Zhu, M. (2017): "Effects of yoga on body composition and static balance ability of middle-aged women," Fujian Sports Technology, VoL.30, No.03, pp.39-41+44.

[13] Zhang, L. H., Xu, X. G. (2018): "Experimental study on the effects of yoga practice on the level of physical function and mental health of women aged 35 to 50 ," Shandong Sports Technology, VoL.32, No.04, pp.88-89.

[14] Ma, Y. (2015): "Comparative study on the effects of yoga and calisthenics on the body shape of middle-aged women," Journal of Shandong Education College, VoL.25, No.04, pp.61-63. 